\title{
Spectrophotometric and Thermodynamic Studies of the Inclusion Complexation of Thiourea Substrate with Hydroxypropyl- $\beta$-cyclodextrin
}

\author{
INAS EL HASSAN ${ }^{\mathrm{a}}$, AHMAD ALLOUCH ${ }^{\mathrm{a}}$, ADIB ABOU DALLE ${ }^{\mathrm{a}}$, \\ HANNA El-NAKAT $^{\mathrm{b}}$ and FAWAZ EL OMAR ${ }^{\mathrm{a}^{*}}$
}

${ }^{a}$ Laboratory of Applied Chemistry (LAC), Faculty of Science III, Lebanese University, P.O. Box 826, Tripoli, Lebanon

${ }^{\mathrm{b}}$ Department of Chemistry, Faculty of Science, University of Balamand, P.O. Box 100, Tripoli, Lebanon

fomar@ul.edu.lb

Received 21 February 2013 / Accepted 19 March 2013

\begin{abstract}
A simple and fast spectrophotometric method has been used to determine the thermodynamic parameters of the inclusion complex formed between $N$-(2-ethylphenyl)- $N$ '- $(2$ methylphenyl) thiourea, a hydrophobic substrate trap and hydroxypropyl- $\beta$-cyclodextrin (HP- $\beta-\mathrm{CD}$ ). The overall association constants have been calculated at different temperatures using the Scott's method and are found to decrease with increase in temperature. The free energy change $\left(\Delta \mathrm{G}^{\circ}\right)$ and the enthalpy of formation $\left(\Delta \mathrm{H}^{\circ}\right)$ as well as the entropy $\left(\Delta \mathrm{S}^{\circ}\right)$ have been determined for the various inclusions. The method has been applied with satisfactory precision; the values of relative standard deviations did not exceed $2 \%$.
\end{abstract}

Keywords: Thiourea, Inclusion complex, Cyclodextrin, Association constant

\section{Introduction}

$N$-(2-ethylphenyl)- $N^{\prime}$-(2-methylphenyl) thiourea belongs to the thiurea compounds family which are active traps of the heavy metals and play an important role in the field of asymmetric organocatalysis ${ }^{1}$. Bifunctional chiral thioureas, have emerged as a successful class of organocatalysts for a variety of asymmetric transformations, such as the cyanosilylation of ketones ${ }^{2}$, Strecker reactions ${ }^{3}$, Michael additions ${ }^{4}$ and hydrophosphonylation of imines ${ }^{5}$. Their success as bifunctional organocatalysts is based upon their ability to function as hydrogen-bond donors and to incorporate of additional basic or acidic activating groups ${ }^{6}$.

Cyclodextrins (CD) are a family of cyclic oligosaccharides containing $6(\alpha), 7(\beta), 8(\gamma)$ or more glucose residues and are characterized by a truncated cone shape ${ }^{7}$. Cyclodextrin molecules consist of secondary hydroxyl groups extending from the wider edge while the 
primary groups from the narrow edge. This gives cyclodextrin molecules a hydrophilic outer surface, whereas the lipophilicity of their central cavity is comparable to an ethanolic solution ${ }^{8,9}$. Natural cyclodextrins show limited aqueous solubility due to the strong intermolecular hydrogen bonding in the crystal state. Substitution of any of the hydrogen bond-forming hydroxyl groups, greatly improves their aqueous solubility ${ }^{10}$. CD derivatives of interest include the hydroxypropyl derivatives (i.e. HP- $\alpha$-CD, HP- $\beta$-CD and HP- $\gamma$-CD), the randomly methylated-CD and sulfobutylether- $\mathrm{CD}^{11-15}$.

Cyclodextrins are widely used as trap molecules in the pharmaceutical, agrochemical, food and cosmetic industries ${ }^{16}$. They are used as complexing agents that encapsulate a variety of poorly water-soluble substrates inside their cavity through non-covalent bonds to form inclusion complexes resulting in an increase in their apparent water solubility ${ }^{17}$. The forces involved in the complex formation are the hydrogen bonding, the Vander Waals' interaction and the charge transfer interaction ${ }^{18}$. The physicochemical properties of the free cyclodextrin molecule are different from those in the complex ${ }^{19}$. This study involves the determination of the association constants, free energy changes, enthalpies of formation and entropies of the complex formed at different temperatures.

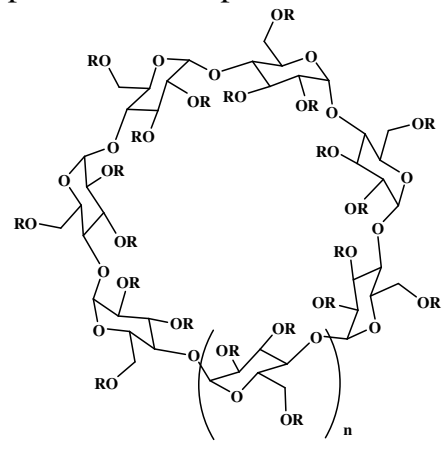

a) $\mathrm{n}=\mathbf{1} ; \mathbf{R}=\mathrm{CH}_{2} \mathrm{CHOHCH}_{3}$

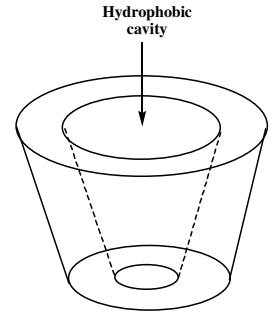

b)

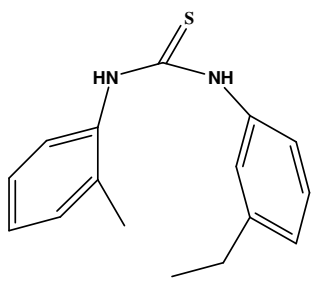

c)

Figure 1. (a) Chemical structure of hydroxypropyl- $\beta$-cyclodextrin (HP- $\beta$-CD); (b) truncated cone shape of (HP- $\beta$-CD; (c) $N$-(2-ethylphenyl)- $N$-(2-methylphenyl) thiourea

\section{Experimental}

The preparation and purification of $N$-(2-ethylphenyl)- $N$-(2-methylphenyl) thiourea substrate was prepared according to the procedure reported in the literature ${ }^{20}$. HP- $\beta$-CD was purchased from Sigma-Aldrich Company. All solvents and materials used throughout this study were of analytical grade and used as such. All laboratory reagents were freshly prepared. Water was purified by triple distillation.

\section{Apparatus}

Double beam UV-1800 (Schimadzu UV-VIS, Japan) spectrophotometer with matched $1 \mathrm{~cm}$ quartz cells was used for all the spectrophotometric measurements. The wavelength of UV detector was set at $220 \mathrm{~nm}$.

\section{Preparation of solutions}

Substrate was accurately weighed, transferred to volumetric flasks and dissolved in a solvent (water, propan-2-ol, acetonitrile; 1/3 volume each) to make individual stock solutions of $10 \mathrm{mmol} / \mathrm{L}$. The stock solutions was stored at $4{ }^{\circ} \mathrm{C}$ and was further diluted with the same solvent to obtain working solutions. 


\section{Preparation of inclusion complexes}

For each measurement, cyclodextrin and substrate was mixed and shaken for $10 \mathrm{~min}$ to obtain a stable state of solubilization.

\section{Absorption spectra}

Schimadzu UV-VIS spectrophotometer (UV-1800) was employed to determine the wavelength of maximum absorption for the substrate in solvent. It was found to be $220 \mathrm{~nm}$.

\section{Standard curves}

For calibration, a $10 \mathrm{mmol} / \mathrm{L}$ mother solution of substrate in solvent was used. A series of $5 \mathrm{~mL}$ solutions of concentrations between 0.1 and $10 \mathrm{mmol} / \mathrm{L}$ were prepared and left at room temperature $\left(25^{\circ} \mathrm{C}\right)$ for $10 \mathrm{~min}$. Absorbance was measured at $220 \mathrm{~nm}$ for each solution against a blank solution.

\section{Association constant $\mathrm{Ka}$, molar absorptivity and free energy change}

Scott's plot method was employed ${ }^{21}$. From the initial equimolar $(10 \mathrm{mmol} / \mathrm{L})$ aqueous solutions of HP- $\beta$-CD and the substrate, serial volumes of 0 to $4.5 \mathrm{~mL}$ of HP- $\beta$-CD solution was transferred to different test tubes. $0.25 \mathrm{~mL}$ of the substrate was added to each test tube and completed to $5 \mathrm{~mL}$ by addition of the necessary volumes of solvent. The method is based on the graphical representation of curves, obtained by means of the experimental measurements from a chemical system in equilibrium using Origin 6.0 professional program. The procedure was continued as described for the calibration and was further analysed at temperatures of $10,40,55$ and $70{ }^{\circ} \mathrm{C}$.

\section{Results and Discussion}

The complex was formed instantaneously; constant absorbance readings have been obtained after 10 minutes of standing at room temperature $\left(25^{\circ} \mathrm{C}\right)$ and remained constant for at least $24 \mathrm{~h}$ (Figure 2). At $220 \mathrm{~nm}$, linear relationships have been obtained (Correlation coefficient, $\mathrm{r}=$ 0.9993 ) between the absorbance and the concentrations over the $20-100 \mu \mathrm{mol} / \mathrm{L}$ range. The regression equation of the line as derived using the method of least squares ${ }^{22}$ is:

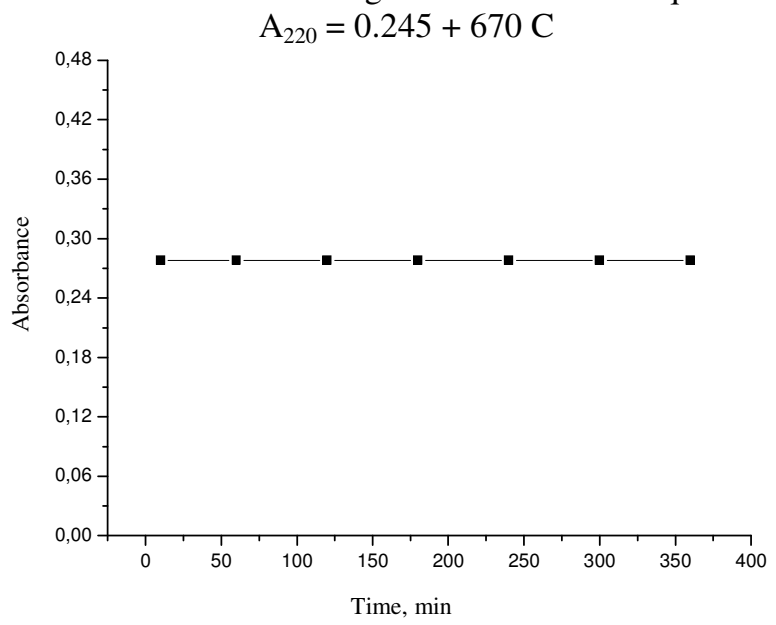

Figure 2. Absorbance-Time relationship for $N$-(2-ethylphenyl)- $N$ '-(2-methylphenyl) thiourea -HP- $\beta$-CD inclusion complex 
Where $\mathrm{A}_{220}$ is the absorbance at $220 \mathrm{~nm}$ and $\mathrm{C}$ is the concentration of $N$-(2-ethylphenyl)$N^{\prime}$-(2-methylphenyl) thiourea. The slope of the calibration curve reflects the sensitivity of the procedure. The standard deviation was calculated to be $3.87298 \times 10^{-4}$.

The absorbance of the complex obtained experimentally was used to calculate the association constants $(\mathrm{Ka})$ of the substrate-HP- $\beta$-CD complex at different temperatures using scott's method ${ }^{21}$ which, like the Benesi-Hildebrand method ${ }^{23}$, depends on the experimental condition in which one of the two components species should be present in large excess. Accordingly, its concentration is virtually unaltered upon the formation of an inclusion complex. According to Scott's equation (Eq. 1), the $[\mathrm{HP}-\beta-\mathrm{CD}] / \Delta \mathrm{A}_{\text {obs }}$ have been plotted against [HP- $\beta$-CD] (Figure 3) showing a linear correlation an indication of $1: 1$ inclusion complex. The slope of the plot $\left(1 / \Delta \mathrm{A}_{\max }\right)$ and the intercept with the vertical axis $\left(1 / K a \cdot \Delta \mathrm{A}_{\max }\right)$ allow the calculation of the association constants $(\mathrm{Ka})$ at different temperature.

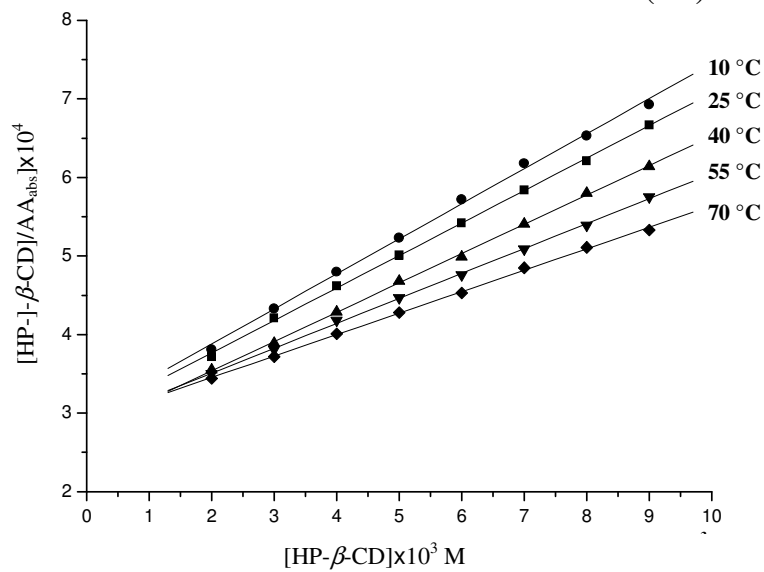

Figure 3. Scott's plot for substrate with HP- $\beta$-CD inclusion complex, showing overall association constants at different temperatures

$$
[\mathrm{HP}-\beta-\mathrm{CD}] / \Delta \mathrm{A}_{\mathrm{obs}}=[\mathrm{HP}-\beta-\mathrm{CD}] / \Delta \mathrm{A}_{\max }+1 / K a \cdot \Delta \mathrm{A}_{\max }
$$

Knowing ka, it becomes possible to graphically obtain the standard enthalpy change, $\Delta H^{\circ}$, of an inclusion interaction by plotting $\log \mathrm{Ka}$ versus $1 / \mathrm{T}$ in (Eq. 2$)^{24}$ and determine the slope from Figure 4.

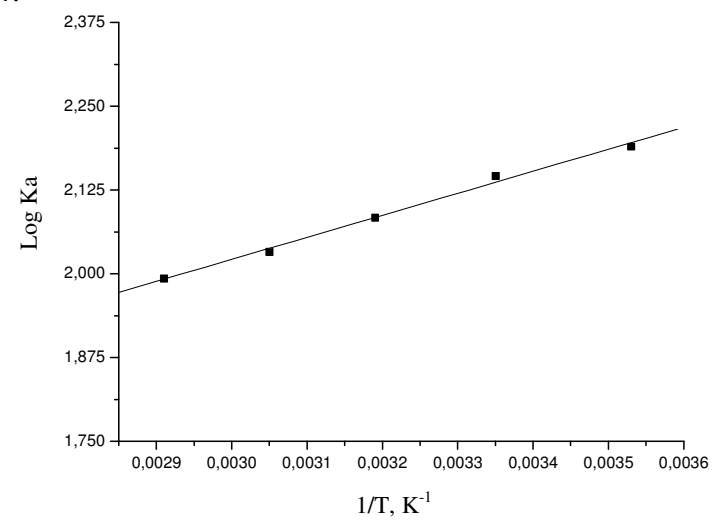

Figure 4. $\log K a$ of the inclusion complex versus $1 / \mathrm{T}$ 


$$
\log K a=\frac{\Delta H^{\circ}}{2.303 \mathrm{RT}}+\text { constant }
$$

As well, the standard free energy, $\Delta G^{\circ}$, is calculated from $K a$ according to Eq. 3 which, in turn, leads to the determination of the standard entropy change, $\Delta \mathrm{S}^{\circ}$, as shown in Eq. 4:

$$
\begin{aligned}
& \Delta G^{\circ}=-\mathrm{RT} \ln K a \\
& \Delta G^{\circ}=\Delta H^{\circ}-\mathrm{T} \Delta S^{\circ}
\end{aligned}
$$

The thermodynamic parameters of the studied inclusion complex are presented in Table 1. All the slopes and intercepts used to calculate these parameters have been determined statistically by the method of least squares. Table 1 shows that the association constants have been observed to decrease with increase in temperature which is in agreement with earlier studies ${ }^{25}$.

Table 1. Association constants $(K a)$, standard free energy $\left(\Delta G^{\circ}\right)$, standard enthalpy $\left(\Delta H^{\circ}\right)$ and standard entropy $\left(\Delta S^{\circ}\right)$ of the substrate-HP- $\beta$-CD inclusion complex at different temperatures

\begin{tabular}{ccccc}
\hline $\begin{array}{c}\text { Temperature } \\
\mathrm{K}\end{array}$ & $K a$ & $\begin{array}{c}\Delta G^{0} \\
\mathrm{Mcal} / \mathrm{mol}\end{array}$ & $\begin{array}{c}\Delta H^{0} \\
\mathrm{kcal} / \mathrm{mol}\end{array}$ & $\begin{array}{c}\Delta S^{0} \\
\mathrm{cal} / \mathrm{deg} / \mathrm{mol}\end{array}$ \\
\hline 283 & 152 & -2.829 & - & 4.682 \\
298 & 140 & -2.930 & -1.504 & 4.785 \\
313 & 127 & -3.017 & - & 4.834 \\
328 & 108 & -3.056 & - & 4.732 \\
343 & 94 & -3.101 & - & 4.656 \\
\hline
\end{tabular}

A negative free energy change $\left(-\Delta G^{\circ}\right)$ and a positive entropy change $\left(+\Delta S^{\circ}\right)$ are indicative of a spontaneous reaction ${ }^{26}$. The inclusion complex between the substrate and HP$\beta$-CD occurs spontaneously and a negative $\Delta H^{\circ}$ is itself a proof of such a spontaneous reaction. Andrews and Keefer ${ }^{27}$ had demonstrated that $\Delta H^{\circ}$ and $\Delta S^{\circ}$ generally become more negative as the association constant for the complexation increases. Table 2 demonstrates the accuracy of the method.

Table 2. Results for regression equation $(\mathrm{y}=\mathrm{a}+\mathrm{bc})$ of the substrate-HP- $\beta$-CD inclusion complex at different temperatures, where $\mathrm{c}$ is the concentration of the HP- $\beta$-CD

\begin{tabular}{lccccc}
\hline \multirow{2}{*}{ Parameter } & \multicolumn{5}{c}{ Temperature, $\mathrm{K}$} \\
\cline { 2 - 6 } & 283 & 298 & 313 & 328 & 343 \\
\hline Number of measurments & 9 & 9 & 9 & 9 & 9 \\
Regression equation (y) & & & & & \\
Slope (b) & 0.0450 & 0.0414 & 0.0363 & 0.0313 & 0.0273 \\
Error on (b) $\times 10^{4}$ & 6.6855 & 3.3242 & 5.3715 & 3.1605 & 3.5375 \\
Error on (a) $\times 10^{4}$ & 2.9613 & 2.9394 & 2.8547 & 2.8988 & 2.9061 \\
Error on (a) $\times 10^{6}$ & 3.7560 & 1.8674 & 3.0274 & 1.7753 & 2.1077 \\
Corelation coefficient (r) & 0.9992 & 0.9998 & 0.9992 & 0.9996 & 0.9995 \\
Standard deviation $\times 10^{6}$ & 5.5489 & 2.7591 & 4.4583 & 2.6232 & 2.2926 \\
\hline
\end{tabular}

\section{Reproducibility}

The reproducibility of the methods has been determined by replicate analysis of three separate solutions of the working standard. The results have proven satisfactory with relative standard deviations not exceeding $2 \%$. 


\section{Conclusion}

Thiourea substrates are known for being traps for heavy metals and accordingly may be used as filters or as means to enhance the measurement of heavy metal concentration. The poor solubility of such substrates continues to impact the development of such potential nonwater soluble trap molecules candidates ${ }^{28}$.

In this study, the mechanism of inclusion complex formation of $N$-(2-ethylphenyl)- $N$ '(2-methylphenyl) thiourea with HP- $\beta$-CD has been studied. The dependence of inclusion complex on temperature has been investigated and trends in thermodynamics parameters have been determined over a wide range of temperature. It is evident from the apparent association constants that the extent to which the inclusion complexation is favoured depends, not only on the polarity and structure of the substrate molecule, but also on the temperature of the solution. The thermodynamic data proves the formation of the inclusion complex and that the process is essentially enthalpy driven.

In addition, this study demonstrated that UV-VIS Spectrophotometry remains an effective, fast and accurate method for measurements aside its simplicity as compared to other methods.

\section{References}

1. Dalko P I and Moisan L, Angew Chem Int., 2004, 43(39), 5138-5175.

2. Fuerst D E and Jacobsen E N, J Am Chem Soc., 2005, 127, 8964-8965.

3. Tsogoeva S B, Hately M J, Yalalov D A, Meindl K, Weckbecker C and Huthmacher K, Bioorg Med Chem., 2005, 13(19), 5680-5685.

4. Hoashi Y, Yabuta T, Yuan P, Miyabe H and Takemoto Y, Tetrahedron, 2006, 62(2-3), 365-374.

5. Joly G D and Jacobsen E N, J Am Chem Soc., 2004, 126(13), 4102-4103.

6. Steele M R, Monti C, Gennari C, Piarulli U, Andreoli F, Vanthuyne N and Roussel C, Tetrahedron: Asymmetry, 2006, 17(6), 999-1006.

7. Szejtli J, Chem Rev., 1998, 98(5), 1743-1754.

8. Szejtli J, Cyclodextrin Technology, Kluwer Academic Publisher, Dordrecht, 1988, Chap. 2.

9. Stella V J and Rajewski R A, Pharm Res., 1997, 14(5), 556-567.

10. Hakkarainen B, Fujita K, Immel S, Kenne L and Sandstrom C, Carbohydr Res., 2005, 340(8), 1539-1545.

11. a) Loftsson T and Brewster M E, J Pharm Sci., 1996, 85(10), 1017-1025; b) El Hassan I, Allouch A, Abou Dalle A, Tabcheh M, El-Nakat H and El Omar F, Asian J Res Chem., 2012, 5(6), 718-721

12. Uekama K, Hirayama F and Irie T, Chem Rev., 1998, 98(5), 2045-2076.

13. Szejtli J, Cyclodextrins and their inclusion complexes, Akademiai Kiadó, Budapest, 1982.

14. Rajewski R A and Stella V J, J Pharm Sci., 1996, 85(11), 1142-1169.

15. Irie T and Uekama K, J Pharm Sci., 1997, 86(2), 147-162.

16. Roux M, Perly B and Djedaini P F, Eur Biophys J., 2007, 36(8), 861-867.

17. a) Loftsson $\mathrm{T}$ and Duchêne D, Int J Pharm., 2007, 329(1-2), 1-11; b) Allouch A, El Hassan I, Abou Dalle A, El-Nakat H and El Omar F, Chem Sci Trans., 2013, 2(2), DOI:10.7598/cst2013.402.

18. Liu L and Guo Q-X, J Inclusion Phenom Macrocyclic Chem., 2002, 42, 1-14. 
19. Arun R, Ashok Kumar C K and Sravanthi V, Sci Pharm., 2008, 76, 567-598.

20. Bellec N, Lorcy D and Robert A, Synthesis, 1998, 10, 1442-1446, doi: 10.1055/s1998-2183.

21. Scott R L, Recueil des Travaux Chimiques des Pays-Bas, 1956, 75, 787, DOI: 10.1002/ recl.19560750711.

22. Wolberg J, Data Analysis Using the Method of Least Squares: Extracting the Most Information from Experiments, Springer, Berlin Heidelberg New York, 2005.

23. Benesi H A and Hildebrand J H, J Amer Chem Soc., 1949, 71(8), 2703-2707.

24. Adikwu M U, Ofokansi K C and Attama A A, Chem Pharm Bull., 1999, 47(4), 463-466.

25. Al-Obeidi F A and Borazan H N, J Pharm Sci., 1976, 65(7), 982-985.

26. Martin A N, Swarbrick J and Cammarata A, Physical Pharmacy, $3^{\text {rd }}$, Lea and Febiger, Philadelphia, 1983, 108.

27. Andrews L J and Keefer R M, J Amer Chem Soc., 1949, 71(11), 3644-3647.

28. Kola I and Landis J, Nat Rev Drug Discov., 2004, 3(8), 711-715. 